\title{
Long-delay spatial discrimination learning in monkeys (Cebus apella)
}

\author{
M. R. D'AMATO, J. BUCKIEWICZ, and M. PUOPOLO \\ Rutgers University, New Brunswick, New Jersey 08903
}

\begin{abstract}
Two variables determined whether monkeys were capable of learning a cue-correlated spatial discrimination in a T-maze with a 30-min delay of reinforcement: the degree of preexisting preference for the $\mathrm{S}-$ arm, and the location in which the animals spent the reinforcement delay (home cage or test room). Animals that had only a mild preference for S- and spent the delay interval in their home cages acquired the spatial discrimination efficiently and maintained a high level of performance. Animals that entered training with a strong preference for Sand/or spent the delay interval in the test room either showed no sign of learning the spatial discrimination or, after giving some indication of learning, reverted to almost exclusive choice of S-.
\end{abstract}

In a recent study we reported that a conditioned preference for one arm of a T-maze could be established in a single trial with $30 \mathrm{~min}$ separating exposure to the T-maze arm and receipt of reward in the startbox (D'Amato \& Buckiewicz, 1980). The robustness of this one-trial long-delay conditioned preference suggested the possibility that monkeys might also learn a longdelay discriminative response (learning to choose one arm of the T-maze) efficiently under similar experimental conditions. The present experiments were addressed to this issue.

\section{EXPERIMENT 1}

In this study the experimental conditions were maintained as closely as possible to those that produced the one-trial long-delay conditioned preference.

\section{Method}

Apparatus. The apparatus was the same T-maze employed in the D'Amato and Buckiewicz (1980) study. Transparent guillotine doors were located at the entrance of the arms, and a startbox was formed by a third transparent guillotine door located in the stem. The top of the maze was enclosed with transparent Plexiglas, and stainless steel bars formed the floor of the maze. The animals were introduced into the T-maze and removed from it through doors that formed the end wall of each arm and the rear wall of the stem, which was painted dark gray. The side and rear walls of the right arm were black; the left arm was vertically striped with alternating gray and white $5-\mathrm{cm}$ bars. A small test room housed both the T-maze and the holding cage (similar to the living cages) in which the animals spent the delay period.

Subjects. The subjects used in this and subsequent experiments were adult Cebus apella monkeys. Some were laboratory born, and others were wild born; some had an enormous amount

This work was supported by NSF Grant BNS 78-24644. Reprints may be obtained from M. R. D'Amato, Department of Psychology, Rutgers University, Busch Campus, New Brunswick, New Jersey 08903. of previous experience in a five-key computer-controlled discrimination apparatus, and others had little or no previous experimental experience other than the conditioned preference study (D'Amato \& Buckiewicz, 1980).

Three animals were trained on a simple cue-correlated spatial discrimination response with virtually immediate reward. A second group of three animals received identical training, except that reinforcement was delayed for $30 \mathrm{~min}$. Throughout the experiment, the animals, which ranged in age from 4 to about 17 years, were housed individually and maintained at $85 \%-95 \%$ of their full-ration body weights. Of the six, Dondi and Olive were females.

Procedure. Spatial preference test. On Day 1, all animals were given a 3-min baseline preference test to determine the nonpreferred arm of the T-maze. The animal was introduced into the startbox and, after the startbox door was raised, it was allowed $3 \mathrm{~min}$ to explore the T-maze. A percent preference score was calculated for each arm by dividing the amount of time spent in that arm by the total amount of time spent in both arms, multiplied by 100 ; time spent in the stem of the T-maze was not considered. For all animals, S+ was defined to be the nonpreferred arm, as determined by the baseline preference test.

Instrumental training. On a typical training trial, the animal was introduced into the startbox, and $30 \mathrm{sec}$ later the startbox door was raised and the animal was permitted to choose the left (striped) or the right (black) arm. Choice of an arm was defined as penetration into an arm sufficient to activate a contact circuit wired through the floor bars. Following a choice response, the animal remained in the chosen arm for 1 min. After a correct response, subjects of the "immediate-reward" group were removed from the arm and placed in the startbox of the T-maze, in which they found a metal cup containing 15 raisins. After an incorrect choice response, the animals were removed from the arm and spent a 1 -min period in the carrying cage facing a corner of the test room.

The subjects of the delayed-reward group were treated in the same fashion, except that a 30-min delay separated removal from the arm of their choice and receipt of reward in the startbox of the T-maze (after correct responses) or placement in the carrying cage for a 1-min period (after incorrect responses). The 30 -min interval was spent in the holding cage located in the test room.

All animals were run 1 trial/day until the criterion of two successive 10-trial blocks with at least $90 \%$ correct responses was reached or until a total of 100 free-choice trials was admin- 
istered. During Days 1-6, a second, forced, trial was given to the correct side of the T-maze if the animal had been incorrect on the free-choice trial. Similar forced trials were reinstituted during Days 61-65 for the three subjects of the delayed-reward group.

\section{Results and Discussion}

Despite strong initial preferences for $\mathrm{S}-$, the three animals in the immediate-reinforcement group (Dondi, Olive, and Sam) acquired the spatial discrimination rapidly, in 20,40 , and 40 trials, respectively (not counting the criterial trials).

The results were quite different in the case of the 30-min-delay animals. Pete had a particularly strong initial preference for $\mathrm{S}_{-}$, and he failed to make a single correct response during the entire 100 free-choice trials. Roscoe averaged only $30 \%$ correct responses over the terminal 20 free-choice trials (Figure 1). Only Kip showed some signs of learning, reaching $100 \%$ correct on the fourth block of 10 trials. However, his performance deteriorated badly thereafter and was only at the $10 \%$-correct level by the end of the 100 free-choice trials. The cyclic behavior evident in Kip's and Roscoe's acquisition functions is uncharacteristic of T-maze learning with immediate reward.

Although the results of the 30-min-delay subjects were not encouraging, Kip's performance suggested the possibility that the animals were capable of acquiring the spatial discrimination, despite the 30 -min delay, but that this potential was attenuated by unidentified sources of interference. Previous work in our laboratory has shown that, when animals are required to spend the reinforcement delay in the experimental apparatus, the discriminative performance of monkeys on a well learned visual discrimination task suffers greatly, a result attributed to delay-induced aversiveness becoming associated with S+ (Cox \& D'Amato, 1977; D'Amato \& Cox, 1976). Although the animals in the present study

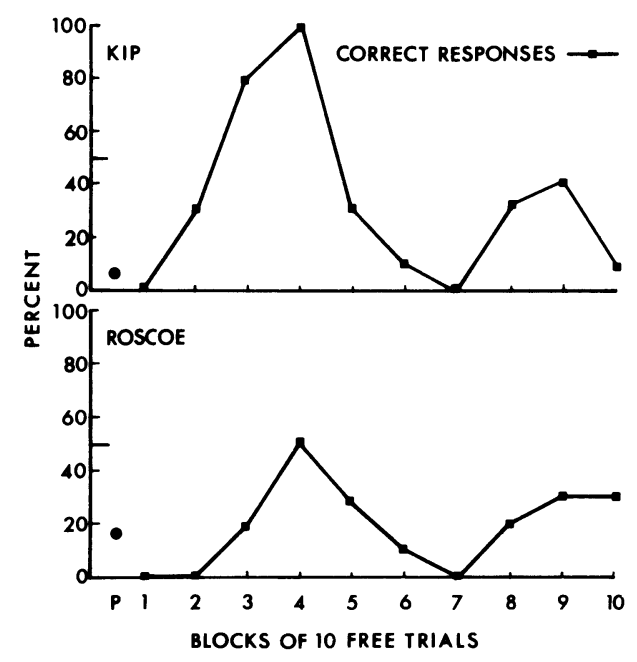

Figure 1. Baseline preference $(P)$ for the $S+$ arm and percent correct responses for two of the three subjects that received a 30-min reinforcement delay in Experiment 1. did not spend the 30-min delay period within the T-maze apparatus, they were confined within the test room, a procedure that seemed to be successful in the case of the conditioned preference study (D'Amato $\&$ Buckiewicz, 1980). However, that study lasted only a few days, possibly too few for the animals to discriminate the reward-delay interval. The next experiment addressed the issue of whether long-delay discrimination learning could be facilitated by eliminating or reducing any aversiveness that might be generated by the rewarddelay interval.

\section{EXPERIMENT 2}

The method employed to reduce the potential aversiveness of the reward-delay interval was to have the animal spend the 30-min delay in its home cage in the colony room. A similar procedure was used by Lett (e.g., 1973, 1975), although the theoretical basis for its employment was quite different.

\section{Method}

Apparatus and Subjects. The apparatus was the same as that employed in Experiment 1. The four monkeys ranged in age from 3 to about 17 years; Peewee was the only male.

Procedure. A 3-min spatial preference test was administered to determine each animal's preference for the right (black) or the left (striped) arms. For all animals, the nonpreferred arm subsequently served as $\mathrm{S}+$.

Spatial discrimination training generally followed the procedure employed in Experiment 1, except that (1) the animal remained in the arm of its choice for 10 rather than $60 \mathrm{sec}$, (2) after correct responses, the animal was rewarded with 20 rather than 15 raisins, which were presented in the center section of the T-maze at the choice point, with both transparent guillotine doors closed, and (3) after incorrect responses, the animal spent a $30-\mathrm{sec}$ period in the center section of the T-maze with both guillotine doors closed without reward or the reward cup present (cf. Lett, 1973, 1975).

On the basis of the baseline spatial preference score, two animals were assigned to the home-cage condition and two to the test-room condition. The animals in the former group spent the 30-min delay-of-reinforcement interval in their home cages, whereas the two animals in the latter condition spent the delay interval in the holding cage located in the test room. One training trial was adminstered each day, except that on Days 1-6, if the animal failed to make a correct response on the initial trial, it was given a second, forced, trial to the correct arm.

\section{Results and Discussion}

Percent correct responses over the 100 free-choice trials are shown in Figure 2, along with the baseline spatial preference test. The choice behavior of the four animals (Figure 2) seems quite disparate, but closer inspection of the results reveals a suggestive pattern. First, the two animals (Peewee and Clea) in the homecage condition performed considerably better than the two that spent the 30 -min delay interval in the test room. Further, the two animals that entered spatial discrimination training with a weak preference for the incorrect alternative (Peewee and Poe) performed better than their counterparts that had a strong preference for $\mathrm{S}-$. Thus it appears that the location in which the 

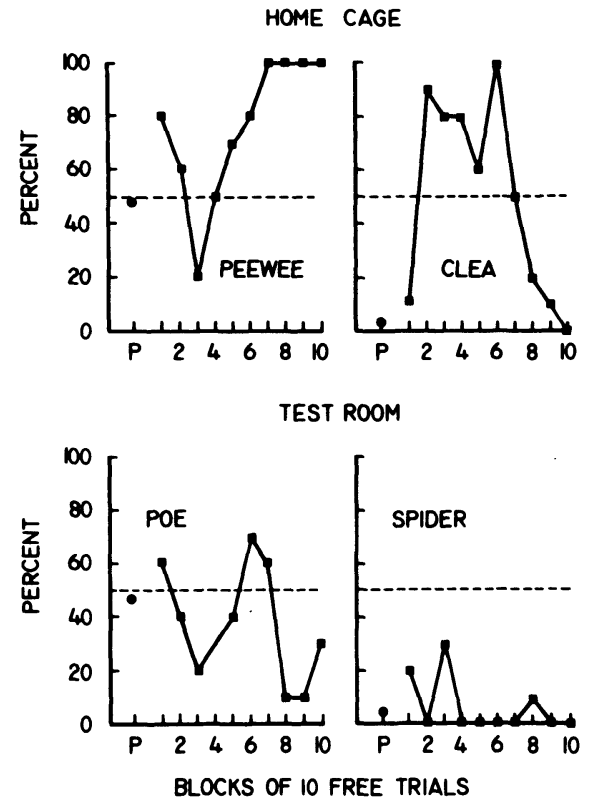

Figure 2. Baseline preference (P) and percent correct responses in Experiment 2. The 30-min reinforcement delay was spent either in the animals' home cages or in the test room.

animal spends the delay period and the strength of initial preference for $\mathrm{S}-$ can importantly affect longdelay T-maze learning. Both of these variables took on favorable values in the case of Peewee, and learning occurred, reaching an asymptotic level of $100 \%$ correct responses. On the other hand, Spider, for which both variables took on unfavorable values, made only one correct response during the last 60 training trials.

Like Kip in Experiment 1, Clea, after reaching a level of $100 \%$ correct responses in the sixth block of trials, subsequently declined to $0 \%$ correct. This perplexing cyclic behavior is also evident in Poe's performance. As already mentioned, such nonmonotonic performance is unusual in discrimination learning that employs immediate reinforcement or very short delays.

The results of the present experiment indicate that the home-cage condition can facilitate spatial discrimination learning with a substantial delay of reward, as Peewee's performance can hardly be considered fortuitous. In an attempt to verify this finding, as well as the dependence of long-delay learning on initial preference for $\mathrm{S}_{-}$, an additional four subjects were run in the home-cage condition with a 30-min reinforcement delay.

\section{EXPERIMENT 3A}

\section{Method}

Apparatus and Subjects. The apparatus was the same as that employed in previous experiments. The four subjects ranged in age from 5.5 to about 17 years; two (Hubert and Potato) were males.

Procedure. A 3-min baseline preference test was administered to each animal to determine the nonpreferred arm of the T-maze, which subsequently served as S+. The only differences in the conduct of spatial discrimination training from previous experiments were that (1) the animal was removed from the arm of its choice within 7-10 sec after entering the arm, (2) reward consisted of 20 raisins, presented in the startbox, and (3) after incorrect responses, the animal was confined to the empty startbox for a $1-\min$ period.

One free-choice trial was given daily. During Days 1-15, if the animal was incorrect on the free-choice trial, it was subsequently given a second, forced, trial to the correct side. Three of the animals were run for 50 free-choice trials, the fourth was run for 60 .

\section{Results and Discussion}

Figure 3 presents the spatial preference and the choice data. Headly, who had a very mild initial preference for the incorrect alternative, learned the spatial discrimination in only 10 trials; like Peewee, she maintained an asymptotic level of $100 \%$ correct responses. Jodi had a somewhat stronger preference for $\mathrm{S}-$, but she nevertheless learned the discrimination efficiently and reached a high terminal level, making 31 correct responses in succession, before committing an error on the 60th and final training trial.

Hubert and Potato, both of which had a very strong preference for $\mathrm{S}-$, managed only three correct responses in the 100 free-choice trials they received. In view of the results from animals of previous experiments that began training with a strong preference for $\mathrm{S}-$, there seemed little point in carrying training further. Rather, we thought it more profitable to attempt modification of the spatial preference of one animal and, perhaps, thereby increase its sensitivity to the delayedreinforcement contingencies. A 3-min spatial preference test given after completion of the 50 free-choice trials
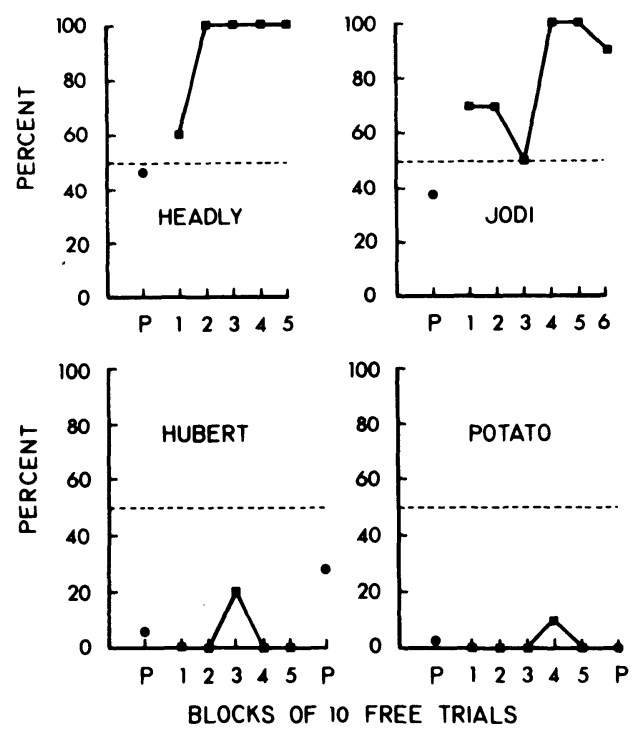

Figure 3. Percent correct responses for each block of 10 free-choice trials of Experiment 3A. Baseline percent preference for the $\mathrm{S}+$ arm is shown, as well as a second preference test given to Hubert and Potato after completion of $\mathbf{5 0}$ free-choice trials (P). 
showed that both animals' strong initial preference for $\mathrm{S}$ - was still largely intact (Figure 3).

To summarize the results of Experiments 1-3A, a total of 11 monkeys were trained with a 30-min delay of reward. Of these, eight spent the delay interval in the test room or began spatial discrimination training with a strong $(65 \%$ or greater) preference for $S$ - or both. Only three monkeys (Peewee, Headly, and Jodi) spent the delay interval in their home cages and did not have an initial strong preference for $\mathrm{S}-$. All of the latter group of subjects but none of the former learned the discrimination. As evaluated by Fisher's exact probability test, this result is highly significant $(p=.006)$.

\section{EXPERIMENT 3B}

Extinction of the strong preference for $\mathrm{S}-$ was attempted in Potato by the simple procedure of allowing the animal free access to the T-maze for a 10-min period on 20 separate sessions. Hubert, who showed a less extreme preference for $\mathrm{S}$ - on the Trial 50 preference test, served as the untreated control. Spatial discrimination training was resumed after the completion of the extinction sessions.

\section{Method}

Extinction. Twenty 10-min extinction sessions were administered, during which the animal was free to explore the T-maze with the two guillotine doors opened and the startbox door closed. The animal's first choice on each extinction session was recorded, as well as its spatial preference during the first 3 min of the 10-min extinction sessions. Removal from the maze at the end of the extinction sessions was from the left and right arms on alternate days. Hubert, the control animal, had his training terminated for a period of time ( 28 days) equal to that required to administer the 20 extinction sessions to Potato.

Resumption of training. An additional 50 free-choice training trials were given (Trials 51-100), 1 per day, conducted in exactly the same manner as those of Experiment 3A. During Days 51-60, Potato received a forced trial to $S+$ if he was incorrect on the free-choice trial; Hubert received the same treatment during Days 61-70. Finally, a 3-min spatial preference test was administered after completion of the 100 th free-choice trial.

\section{Results and Discussion}

During the 20 extinction sessions, Potato's initial turning response was always to the $S-$ arm. Preference for the $S-$ arm, as measured by the spatial preference tests, was initially high, but during the last two sessions, Potato spent more time (76\%) in the S+ arm than in $\mathrm{S}-$. Thus, as measured by the 3 -min preference tests, Potato's preference for S- changed dramatically over the 20 extinction sessions.

The choice data for Trials 51-100 (Figure 4) revealed a remarkable difference in the performance of the two animals. After an initial increase in percent correct responses, Hubert's performance again declined to $0 \%$ correct. In contrast, Potato showed rapid learning of the spatial discrimination, averaging $87 \%$ correct responses over the last 30 training trials. Figure 4 also reveals a

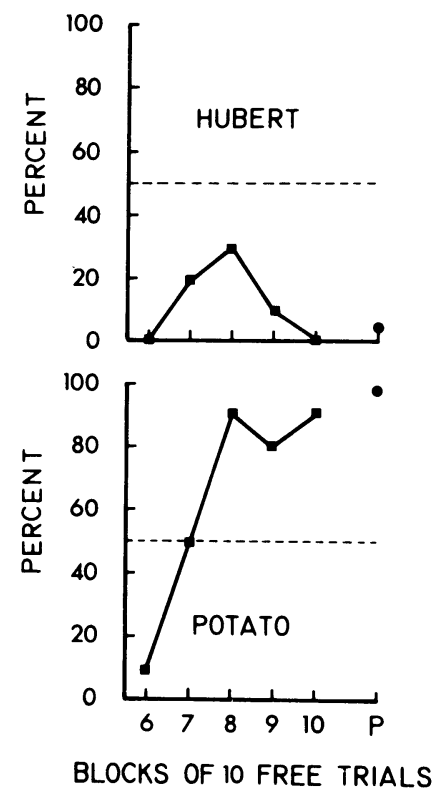

Figure 4. Percent correct responses and terminal preference (P) for the S+ arm in Experiment 3B.

dramatic difference in the final spatial preference scores: Hubert once again displayed almost total preference for S-, whereas Potato's preference was almost exclusively for S+. It seems clear that strong preferences for incorrect alternatives are remarkably resistant to change by delayed contingencies. A discussion of the methodological and theoretical significance of this fact is beyond the scope of the present paper (cf. D'Amato, Safarjan, \& Salmon, in press; D'Amato, Salmon, \& Puopolo, 1981).

\section{REFERENCES}

Cox, J. K., \& D'Amato, M. R. Disruption of overlearned discriminative behavior in monkeys (Cebus apella) by delay of reward. Animal Learning \& Behavior, 1977, 5, 93-98.

D’Aмато, M. R., \& Buckiewicz, J. Long-delay one-trial conditioned preference and retention in monkeys (Cebus apella). Animal Learning \& Behavior, 1980, 8, 359-362.

D'AмAто, M. R., \& Cox, J. K. Delay of consequences and short-term memory in monkeys. In D. L. Medin, W. A. Roberts, \& R. T. Davis (Eds.), Process of animal memory. Hillsdale, N.J: Erlbaum, 1976.

D'Amato, M. R., Safarjan, W. R., \& Salmon, D. Long-delay conditioning and instrumental learning: Some new findings. In N. E. Spear \& R. R. Miller (Eds.), Information processing in animals: Memory mechanisms. Hillsdale, N.J: Erlbaum, in press.

D'Amato, M. R., Salmon, D., \& Puopolo, M. Long-delay visual discrimination learning in monkeys (Cebus apella). Bulletin of the Psychonomic Society, 1981, 18, 89-91.

LETT, B. T. Delayed reward learning: Disproof of the traditional theory. Learning and Motivation, 1973, 4, 237-246.

LETT, B. T. Long delay learning in the T-maze. Learning and Motivation, 1975, 6, 80-90.

(Received for publication June 19, 1981.) 